\title{
CONSIDERAÇÕES SOBRE A APARÊNCIA A PARTIR DE ROUS- SEAU E KANT: APROXIMAÇÕES E DIFERENÇAS
}

\author{
CONSIDERATIONS ABOUT APPEARANCE FROM ROUSSEAU AND KANT: simi- \\ larities and differences
}

CONSIDERACIONES ACERCA DE LA APARIENCIA DE ROUSSEAU Y KANT:
similitudes y diferencias

Zilmara de Jesus Viana de Carvalho

Doutora em Filosofia, UFMA.

ziljesus@yahoo.com.br

\begin{abstract}
RESUMO: A presente investigação visa analisar o tema do refinamento dos costumes no séc. XVIII à luz do pensamento de Rousseau e Kant, assim como o consequente jogo da aparência que o envolve. Considera-se, para tanto, que, se por um lado, tais filósofos tecem, de forma recorrente, considerações sobre a civilidade, entendendo-a como um sintoma do progresso e vendo-a como algo que não pode ser pretendido como o estágio final da humanidade, sob pena do estranhamento do homem em relação ao seu ser, por outro, possuem diferenças insuperáveis em suas abordagens. Sendo assim, nossa pretensão é demonstrar que são precisamente as concepções distintas que estes têm acerca do homem e de seu desenvolvimento que definirão as expectativas que ambos possuem em relação à espécie.
\end{abstract}

PALAVRAS-CHAVE: Civilidade. Aparência. Progresso. Moralidade.

ABSTRACT: This research aims to analyze the theme of refinement of manners in the century. XVIII in the light of the thought of Rousseau and Kant, as well as the consequent appearance of game that involves. It is considered, therefore, that on the one hand, these philosophers analyzes on a recurring basis, consideration of civility, understanding it as a symptom of progress and seeing it as something that can not be intended as the final stage of humanity, on pain of estrangement of man in relation to his being on the other, have insurmountable differences in their approaches. Therefore, our intention is to demonstrate that are precisely the different conceptions they have about the man and his development, outlining the expectations that both have in relation to the species.

KEYWORDS: Civility. Appearance. Progress. Morality.

RESUMEN: Esta presente investigación analiza el tema del refinamiento de las costumbres en el siglo XVIII a la luz del pensamiento de Rousseau y Kant, así como el consecuente juego de apariencia que envuelve. Se considera, por lo tanto, que, por un lado, estos filósofos tejen de manera recurrente, consideraciones sobre la civilidad, entendiéndola como un síntoma de progreso y verla como algo que no puede ser destinado como la etapa final de la humanidad, con pena de extrañamiento del hombre en relación con su ser, en el otro, tienen diferencias insuperables en sus abordajes. Así, nuestra intención es demostrar que son precisamente las concepciones distintas que que estos tienen sobre el hombre y su desarrollo que establecerá las expectativas de que ambos tienen en relación con la especie.

PALABRAS CLAVE: Civilidad. Apariencia. Progreso. Moralidad. 


\section{1 | INTRODUÇÃO}

O tema do refinamento dos costumes nas relações sociais e o consequente jogo da aparência são comuns à filosofia do séc.XVIII. Em Rousseau e em Kant, a referência a essa questão encontra-se em diversos textos, posto que suas análises em torno da noção de progresso são recorrentes e a civilidade é um sintoma claro (para o bem ou para o mal) de tal acontecimento. A visão lúcida das consequências do progresso é compartilhada pelos dois. Entretanto, é também verdade que estes filósofos possuem diferenças insuperáveis em suas abordagens.

Rousseau apresenta uma extrema preocupação com a moralidade humana, vendo no progresso a principal causa da deterioração das virtudes. Entretanto, pode-se dizer que a crítica de Rousseau não é propriamente contra o aumento das luzes, contra o desenvolvimento das ciências e das artes, mas contra um tipo de progresso que sem levar em conta o próprio homem, sem respeitar aspectos determinantes de sua existência, como é o caso da liberdade e da virtude, acaba por ter como consequência a perversão e degeneração da espécie.

Kant, por sua vez, é um defensor do progresso, pois vê neste a condição para o desenvolvimento das disposições naturais humanas voltadas para o uso da razão, e a disposição moral é uma delas. A civilidade seria uma etapa desse longo e lento processo de desenvolvimento, mas não o fim último a ser atingido pela humanidade. Contudo, isso não faz de Kant necessariamente um crítico de Rousseau; ele, em certo sentido, pactua com a crítica rousseauísta, preocupa-se com a perda de esperança que possa ser engendrada na humanidade através do progresso e do consequente predomínio do artificialismo, fruto do melhoramento dos costumes.

Dessa forma, suas diferenças não são maiores, ao que tudo indica, do que aquilo que os aproxima, a saber, pensar o homem a partir de uma perspectiva moral, em uma época em que o progresso científico e seus benefícios, catalizavam as atenções de todos e não as consequências éticas de tal progresso.

Assim, a preocupação com um progresso capaz de conduzir ao velamento daquilo que definiria a própria humanidade, isto é, seu ser e, por conseguinte, destruir o sentido da vida humana, mesmo que em proporções diferentes ou a partir de fundamentações teóricas distintas, é tema peculiar a ambos e merece atenção. Para tanto, pretende-se apontar as críticas que estes tecem ao comportamento do homem em sociedade, uma vez que elas expressam suas preocupações com as consequências de um progresso científico desacompanhado de um desenvolvimento moral; bem como demonstrar que suas divergências radicam, sobretudo, na forma como concebem a natureza humana, esclarecendo como isso irá definir as expectativas que possuem em relação à espécie.

\section{2 | O PROGRESSO E A APARÊNCIA: Rousseau preceptor de Kant}

No Discurso sobre a desigualdade (1755), Rousseau, imbuído do desejo de mostrar como a desigualdade se instala entre os homens, esclarece, logo no prefácio da obra, que a condição de possibilidade para esse exame é compreender quem é o homem, tarefa que, para ser levada a cabo, implicaria em "separar o que pertence à sua própria essência daquilo que as circunstâncias e seus progressos acrescentaram a seu estado primitivo ou nele mudaram [...]" (ROUSSEAU, 1983a, p. 227). Com isso parece, sem maiores dificuldades, admitir para o ser humano, por um lado, uma essência, algo que o possibilitaria defini-lo enquanto tal e, por outro, a modificação daquilo que por natureza ele fora preparado para ser. 
Nessa empreitada, é sabido que Rousseau procura demonstrar como o homem, ao entrar em sociedade, degenera ou, em outras palavras, como degenera à medida que progride. Para sustentar sua tese de que a história humana é uma história do declínio e não do progresso, promove uma reconstrução racional de como o homem vivia antes da sociedade civil, partindo de um artifício metodológico já bem conhecido entre os contratualistas, a saber, o estado de natureza (artifício, diga-se de passagem, também utilizado como ideia reguladora por Kant).

A hipótese do estado de natureza - que para Rousseau não é um estado linear, mas evolutivo, visto que marcado por transformações - possibilita-o mostrar que quanto mais o homem vai se distanciando do seu estado natural, que é, inicialmente, de quase completo isolamento, isto é, quanto mais o processo de socialização vai se intensificando e refinando, ele também vai se corrompendo, ou seja, tornando opaca sua essência, soterrando-a aos poucos, o que implica, por sua vez, num predomínio de relações calcadas na aparência.

A analogia com a estátua de Glauco ilustra bem o quão irreconhecível e distanciado de si mesmo tornou-se o homem após todos os progressos conquistados pela espécie. Com efeito, diz Rousseau (1983a, p. 227) no Discurso sobre a desigualdade:

\begin{abstract}
Como a estátua de Glauco, que o tempo, o mar e as intempéries tinham desfigurado de tal modo que se assemelhava mais a um animal feroz do que a um deus, a alma humana, alterada no seio da sociedade por milhares de causas sempre renovadas, pela aquisição de uma multidão de conhecimentos e de erros, pelas mudanças que se dão na constituição dos corpos e pelo choque contínuo das paixões, por assim dizer mudou de aparência a ponto de tornar-se quase irreconhecível e, em lugar de um ser agindo sempre por princípios certos e invariáveis, em lugar dessa simplicidade celeste e majestosa com a qual seu autor a tinha marcado, não se encontra senão o contraste disforme entre a paixão que crê raciocinar e o entendimento delirante.
\end{abstract}

A preocupação que subjaz à análise de Rousseau (que o move no sentido de investir de forma tão contundente contra o progresso e, por assim dizer, contra o aumento das luzes) é com o efeito colateral mais danoso decorrente desse movimento em direção ao esclarecimento, a saber, a destruição das virtudes, em outras palavras, a deterioração daquilo que permitiria identificar a humanidade em sua essência.

Essa preocupação não é nova, a forma, porém, como Rousseau apresenta sua inquietação e preocupação, forma, ao mesmo tempo, ousada e corajosa, é o que faz, no entanto, toda diferença, sendo, no mínimo, desconcertante, pois abrindo mão de condescender com seus contemporâneos sobre a importância das ciências e das artes, ou ainda sobre o luxo das cortes, opõe-se ao seu restabelecimento, uma vez que entende que o malefício causado por elas à espécie humana - a completa perda das virtudes - foi incomparavelmente maior do que seus propagados benefícios. O preço pago mostrara-se, demasiadamente, caro.

Evidentemente, não se constitui como nossa pretensão refazer os passos de Rousseau no estado de natureza, pretendemos, todavia, extrair alguns de seus elementos que nos ponham em condições de entender a extensão do prejuízo causado pelo progresso denunciado por Rousseau, e a maneira mais viável de fazê-lo se nos afigura como compreender de que homem o genebrino está falando.

Com vistas a isso, cabe observar que a perfectibilidade é apresentada por Rousseau no segundo Discurso (Discurso sobre a desigualdade) como uma das características distintivas do homem, característica que lhe possibilita um certo desenvolvimento no estado de natureza diante das necessidades impostas. Entretanto, isto não é suficiente para associar tal característica ao progresso propriamente dito, com efeito, este é impensável como algo próprio ao homem natural, como inerente a ele, tanto que pergunta Rousseau: 
Que progresso poderia conhecer o gênero humano esparso nas florestas entre os animais? E até que ponto poderiam aperfeiçoar-se e esclarecerem-se mutuamente homens que, não tendo domicílio fixo nem necessidade uns dos outros, se encontrariam talvez, somente duas vezes na vida, sem se conhecer e sem se falar? (ROUSSEAU, 1983a, p. 246).

Nessa perspectiva, embora essa perfectibilidade possa ser pensada como natural, o progresso, por sua vez, é contranatural. O progresso, para acontecer, precisa de certas condições, haja vista que a própria sociabilidade humana também só vai sendo construída mediante tais condições. Lembremos que os homens não só não têm qualquer correspondência entre si, como também não têm sequer a necessidade de tê-la, a própria união macho e fêmea é fortuita, ou seja, tratava-se de seres independentes e sem vida comunitária (ROUSSEAU, 1983 a, p. 247).

Ao contrário de Kant, em que a natureza lança os homens em sociedade, a fim de que possam desenvolver suas disposições naturais para o uso da razão através do conflito, Rousseau (1983a, p. 264) afirma, no segundo Discurso, acerca do estado de natureza, que:

O exemplo dos selvagens que foram encontrados quase todos nesse ponto, parece confirmar que o gênero humano era feito para sempre nele permanecer, que esse estado é a verdadeira juventude do mundo e que todos os progressos ulteriores foram, aparentemente, outros tantos passos para a perfeição do indivíduo e, efetivamente, para a decrepitude da espécie.

Fato é que, segundo Rousseau, fatores diversos concorreram para a modificação da natureza, imprimindo uma nova forma no relacionamento dos homens entre si e, na medida em que essas modificações sofridas pelo meio foram ocorrendo e os homens foram por conta, muito do acaso, sendo forçados a se aproximarem, essa aproximação aos poucos foi substituindo seu antigo modo de vida: eles passaram a se reunir numa mesma habitação, instituir uma espécie de propriedade, pensar suas ações a partir de uma perspectiva moral, desenvolveram uma linguagem e paixões inexistentes até então, engendraram-se na natureza humana (tais como: o amor, o ciúme, o desejo de reconhecimento e, ainda, a vaidade, o desprezo, a vergonha e a inveja). Diz Rousseau (1983a, p. 263) que: "[...] foi esse o primeiro passo tanto para a desigualdade quanto para o vício."

Dispondo todos de uma mesma condição de vida e não havendo nenhum senhorio, qualquer relação de domínio, sendo todos iguais possuidores do mesmo tipo de liberdade, é fácil entender o motivo pelo qual seria este o primeiro passo para a desigualdade. Entretanto, resta investigar por que também para o vício?

Contudo, detenhamo-nos um pouco no tema da liberdade. A liberdade não é apenas uma característica que iguala os homens no estado de natureza, ela se constitui como uma qualidade específica que os distinguem dos demais animais, tão importante nessa distinção quanto a perfectibilidade, de modo que afirma Rousseau (1983a, p. 243) que não é tanto o entendimento quanto a liberdade que os diferencia, ela é que o faz escapar da mera condição de um ser mecanicamente determinado. Quanto a isto esclarece:

A natureza manda em todos os animais, e a besta obedece. O homem sofre a mesma influência, mas considera-se livre para concordar ou resistir, e é sobretudo na consciência dessa liberdade que se mostra a espiritualidade de sua alma, pois a física de certo modo explica o mecanismo dos sentidos e a formação das idéias, mas no poder de querer, ou antes, de escolher e no sentimento desse poder só se encontram atos puramente espirituais que de modo algum serão explicados pelas leis da mecânica. (ROUSSEAU, 1983a, p. 243).

Note-se que é por meio da liberdade e não de uma determinação natural que o homem, ao contrário dos outros animais, pode desviar-se da regra que lhe é prescrita e lembra Rousseau que é com frequência que dela se afasta, em seu próprio prejuízo. Ora, como a liberdade tem impor- 
tância tão peculiar, o agravamento da perversão da natureza humana tem como uma das maiores consequências a instalação de um estado de subjugação, que pode evoluir para um estado de miséria, escravidão e até de sujeição à natureza, conforme afirma Rousseau (1983a, p. 267), também no Discurso sobre a desigualdade, ao declarar que:

Ser e parecer tornaram-se duas coisas totalmente diferentes. Dessa distinção resultaram
o fausto majestoso, a astúcia enganadora e todos os vícios que lhes formam o cortejo.
Por outro lado, o homem, de livre e independente que antes era, devido a uma multidão de
novas necessidades passou a estar sujeito, por assim dizer, a toda a natureza e, sobretu-
do, a seus semelhantes dos quais num certo sentido se torna escravo, mesmo quando se
torna senhor: rico, tem necessidade de seus serviços; pobre, precisa de seu socorro [...].

Com relação ao engendramento do vício, atentemos que, num primeiro momento, Rousseau pondera, na mesma obra, que os homens não poderiam, no estado de natureza, ser considerados nem bons nem maus, tampouco dotados de vícios ou de virtudes, pelo simples fato de não haver entre eles "qualquer espécie de relação moral, ou de deveres comuns" (ROUSSEAU, 1983a, p. 251).

Mais adiante reitera isto ao criticar Hobbes, que, segundo sua leitura, teria afirmado serem os homens maus no estado de natureza, ao que contra-argumenta afirmando não se poder dizer que estes sejam naturalmente maus, só porque não possuem nenhuma ideia de bondade, ou que sejam corruptos por não conhecerem a virtude (ROUSSEAU, 1983a, p. 252). Na mesma perspectiva, diz que "os selvagens não são maus precisamente porque não sabem o que é ser bons [...]" (ROUSSEAU, 1983a, p. 252).

Pelas mencionadas passagens, poder-se-ia inferir que o homem, segundo Rousseau, não seria nem bom nem mau no estado de natureza. Ora, que o homem não é mau por natureza parece claro, entretanto, com relação à bondade natural, a questão é mais complexa, pois, na continuidade deste raciocínio, Rousseau (1983a, p. 253) faz a seguinte observação:

\footnotetext{
Não creio ter a temer qualquer contradição, se conferir ao homem a única virtude natural [...]. Falo da piedade, disposição conveniente a seres tão fracos e sujeitos a tantos males como somos; virtude tanto mais universal e útil ao homem quando nele precede o uso de qualquer reflexão, e tão natural que as próprias bestas às vezes dão dela alguns sinais perceptíveis. [...]

Tal é o movimento puro da natureza anterior a qualquer reflexão; tal a força da piedade natural que até os costumes mais depravados tem dificuldade em destruir, porquanto se vê todos os dias, em nossos espetáculos, emocionar-se e chorar por causa das infelicidades de um desafortunado, aquele mesmo que, se estivesse no lugar do tirano, agravaria ainda mais os tormentos de seu inimigo [...].
}

A piedade natural, diz Rousseau, foi conferida ao homem para apoio à razão e os homens seriam monstruosos apesar de toda a sua moral se a natureza lhes tivesse privado da referida piedade Acrescenta ainda que todas as virtudes sociais decorrem desta qualidade. Sendo assim, antecedendo qualquer reflexão, antecederia também a noção de moralidade, forjada artificialmente pelos homens mediante sua aproximação uns com os outros, servindo, não obstante, como fundamento da moral sob pena, conforme ressaltamos acima, de os homens se tornarem verdadeiros monstros, na medida em que por ela a humanidade seria marcada e vinculada pela compaixão.

Há que se observar, contudo, que o homem é determinado por natureza não apenas pela presença da piedade, porém, além desta, por um outro instinto originário, o amor de si. Quanto ao amor de si, estaria referido ao sentimento de autopreservação, que, articulado à piedade, se estenderia ao sentimento de preservação da espécie e não apenas de conservação individual. Considerando-se esses dois instintos originários, de modo algum se pode atribuir ao homem em 
seu estágio inicial, dentro do estado de natureza, uma natureza má. Entretanto, como esse estado, na perspectiva rousseauísta, vai sofrendo transformações, com o surgimento da sociedade a piedade natural vai passando por alterações, o homem passa a ter que exercer a função de juiz e vingador das ofensas recebidas e a piedade tal como era antes já não mais convinha. Porém, como também observa Rousseau (1983a, p. 264), tratando-se inicialmente de um estado menos sujeito a revoluções, é também "o melhor para o homem", que só deve ter saído dele forçado por algum acaso, como enfatiza o genebrino.

Quanto a esse momento, que antecede o desenvolvimento vertiginoso que ocorrerá na sociedade civil no que tange às artes e às ciências, a natureza humana já não era melhor, como atesta Rousseau, contudo ainda tinha a vantagem de buscar na felicidade recíproca com o outro sua segurança, tanto que afirma no primeiro Discurso ou Discurso sobre as ciências e as artes (1750):

Antes que a arte polisse nossas maneiras e ensinasse nossas paixões a falarem a linguagem apurada, nossos costumes eram rústicos, mas naturais. [...] No fundo a natureza humana não era melhor, mas os homens encontravam sua segurança na facilidade para se penetrarem reciprocamente, e essa vantagem, de cujo valor não temos mais noção, poupava-Ihes muitos vícios. (ROUSSEAU, 1983b, p. 336).

Como assevera Rousseau, essa sociedade tranquila do início não perdura e a depravação da natureza humana segue um desenvolvimento contínuo; sufocada a voz da piedade, essa primitiva virtude natural, nascem os interesses próprios em detrimento dos comuns, bem como a inveja, a cobiça, a necessidade de domínio e toda sorte de desigualdades, a ingerência dos vícios em toda sua força. Isto porque a piedade, embora não possa ser extirpada do homem, pode, todavia, ser calada, emudecida, de modo a sobressair-se, desvinculando-se dela, o amor de si, agora sob a feição de amor próprio que, diante dessa nova configuração, é melhor definido como egoísmo. As relações travadas a partir daí são baseadas na ambição, na inveja, na aparência de bondade, em síntese, no desejo de satisfazer os próprios interesses, sobretudo o de lucro, à custa dos outros.

A consequência principal dessa preeminência do amor próprio pode ser sintetizada assim: as relações baseadas puramente na aparência presidiram o ocultamento e esquecimento daquilo que se é, bem como da virtude e de seu cultivo. Os homens se tornaram não apenas desiguais, mas rivais; nasce daí a dominação, a servidão, a violência e o roubo, que se intensificam ainda mais através de um contrato baseado na submissão. Conforme Rousseau (1983a, p. 269), através desse contrato, "todos correram ao encontro de seus grilhões, crendo assegurar sua liberdade, pois, com muita razão reconhecendo as vantagens de um estabelecimento político, não contavam com a suficiente experiência para prever-lhes os perigos [...]"

Com efeito, dispara Rousseau (1983b, p. 335), não sem certa ironia, no primeiro Discurso:

A necessidade levantou os tronos; as ciências e as artes os fortaleceram. Potências da ter-
ra, amai os talentos e protegei aqueles que os cultivam. Povos policiados, cultivai-os; es-
cravos felizes, vós lhe deveis esse gosto delicado e fino com que vos excitais, essa doçura
de caráter e essa urbanidade de costumes, que tornam tão afável o comércio entre vós,
em uma palavra: a aparência de todas as virtudes, sem que se possua nenhuma delas.
Por essa espécie de polidez, tanto mais amável quanto menos afeta mostrar-se [...] nosso
século e nossa nação sobrepujarão todos os tempos e todos os povos [...].

Nesse sentido, o desenvolvimento das relações sociais, culminando na fundação de uma sociedade civil, marcada de forma extrema pela desigualdade, o aumento das luzes, que o impulsionou e por ele também foi favorecido, o consequente progresso das artes e das ciências, foram passos decisivos para a perfeição dos indivíduos, bem como para decrepitude da espécie, ou seja, para 
sua desnaturalização, pois, aumentando o distanciamento do homem de sua natureza, perverteu-a ainda mais, como diz Rousseau (1983b, p. 337), ainda no primeiro Discurso: "[...] nossas almas se corromperam à medida que nossas ciências e nossas artes avançaram no sentido da perfeição."

Mais adiante, porém, deixa transparecer seu mais profundo desejo para a humanidade: "Como seria doce viver entre nós, se a contenção exterior sempre representasse a imagem dos estados do coração, e se a decência fosse a virtude, se nossas máximas nos servissem de regra, se a verdadeira filosofia fosse inseparável do título de filósofo!" (ROUSSEAU, 1983b, p. 335).

Entretanto, entre o dever ser e o ser, entre a consciência de que os homens poderiam e deveriam viver de uma forma distinta da que se instalara, interpunha-se um abismo acentuado pela perda e recusa da verdadeira identidade, conforme é diagnosticado no Emílio (1762): "O homem do mundo está inteiro em sua máscara. Não estando quase nunca em si mesmo, é sempre um estrangeiro e sente-se pouco à vontade quando é obrigado a voltar a si. O que ele é, nada é, o que parece ser é tudo para ele" (ROUSSEAU, 1999, p. 300).

Note-se que a recusa de voltar-se ao que se é, dá-se em função de um estranhamento de si, o homem, estando já tão acostumado a representar um papel, não consegue ajustar-se àquilo que de fato é. Eis o caráter mais nefasto do progresso das luzes. Daí porque é praticamente impossível romper com um mundo habituado às aparências, a ponto de Rousseau insistir no termo "degeneração da espécie". O que, por outro lado, não o faz descartar a possibilidade de uma instância capaz de frear e, por que não dizer, reverter, sob certa medida, o quadro dramático da existência humana: a educação.

\section{3 | KANT LEITOR DE ROUSSEAU: INFLUÊNCIAS E DIVERGÊNCIAS}

Nas Observações sobre o sentimento do belo e do sublime (texto pré-crítico), podemos constatar claramente que Kant concorda não apenas com a preocupação de Rousseau quanto ao artificialismo nas relações humanas, como com o fato da saída para tal situação encontrar-se na educação, uma vez que lá afirma:

[...] vemos nos nossos dias florescer o verdadeiro gosto do belo e do nobre, tanto nas artes, nas ciências, como nos costumes, e somente podemos desejar que o falso brilho, tão facilmente enganador, não nos distancie, de forma inadvertida, da nobre simplicidade. Sobretudo, que o segredo por revelar da educação consiga ser arrancado da antiga ilusão, para elevar desde cedo o sentimento moral no peito de todo jovem cosmopolita, de modo a formar uma sensibilidade activa, que permita evitar que o refinamento vá acabar no prazer fugaz $\mathrm{e}$ ocioso de julgar com mais ou menos gosto o que ocorre fora de nós. (KANT, 2012, p. 89).

Cassirer não se furtou a considerar detidamente esse encantamento de Kant com a crítica rousseauísta, de modo que assim afirma:

O que Kant apreciou em Rousseau é que havia sabido discernir melhor que ninguém entre a máscara do homem e seu autêntico rosto. Também no entender de Kant há inúmeros "bens" aparentes da cultura que não agregam nada ao valor do homem, somente o confundem e o fazem mais problemático quando usurpam seu lugar. Há uma infinidade de coisas que no transcurso do tempo o homem tem tomado de exterior e feito suas, injetando-as dentro de si através da cultura e da tradição, sendo que isto é contrário a sua "verdadeira" natureza [..]. Assim, pois, Kant nunca tomou o conceito de "homem natural" num sentido puramente físico ou histórico, porém em um sentido ético e teleológico. [...] Kant rende honras ao Rousseau ético que, trás todos os ocultamentos e dissimulações, trás todas as máscaras que o homem tem procurado e portado no transcurso de sua história, divisa o "verdadeiro homem", isto é, reconhece e vindica sua peculiar e imutável tarefa. (CASSIRER, 2007, p. 181). 
A análise de Cassirer é, ao que tudo indica, inequívoca, pois o tornar-se civilizado ${ }^{1}$ é para Kant, sem dúvida, sintoma de desenvolvimento das disposições humanas e, nesse sentido, absolutamente desejável, porém de maneira alguma pode ser considerado o fim último pretendido para a humanidade, o seu derradeiro estágio, apenas um degrau necessário para conduzi-lo a tal, tanto assim que diz na Antropologia de um ponto de vista pragmático (1798): "O ser humano está destinado, por sua razão, a estar numa sociedade com seres humanos e a se cultivar, civilizar $e$ moralizar nela por meio das artes e das ciências [...]" (KANT, 2006, p. 219. AK, VII, 324 - 325).

É para a diferença entre civilidade e moralidade que Kant está apontando. Atentemos com mais acuidade às considerações finais tecidas por ele na sétima proposição da Ideia de uma história universal (1784), haja vista que esta diferença ganha destaque. Com efeito, diz:

\begin{abstract}
Mediante a arte e a ciência, somos cultivados em alto grau. Somos civilizados até a saturação por toda espécie de boas maneiras e de decoro sociais. Mas ainda falta muito para nos considerarmos moralizados. Se, com efeito, a idéia de moralidade pertence à cultura, o uso, no entanto, desta idéia, que não vai além de uma aparência de moralidade (Sittenähnliche) no amor à honra e no decoro exterior, constitui apenas a civilização. (KANT, 2003, p. 16. AK, VIII, 26).
\end{abstract}

Assim, Kant reconhece expressamente os problemas do mundo civilizado, o melhoramento dos costumes, o refinamento, as gentilezas e sutilezas, ou seja, as boas maneiras são um terreno fértil para a ocultação do ser, isto é, do que se pensa, do que se quer, do que se sente e, por assim dizer, das reais intenções, em favor do predomínio das aparências, das insinceridades.

Segundo Kant, a experiência é a testemunha por excelência da escolha que fizemos pelo amor próprio, em toda parte é possível ver sinais claros do amado eu. A análise kantiana da opção humana pelo mal, encarnada aí na preocupação dos homens com seus próprios interesses, na vaidade e na arrogância, numa conduta que escamoteia seus reais motivos, é corroborada pela experiência. Se a experiência não é capaz de nos fornecer genuínos exemplos morais, pois não podemos sondar a intenção dos corações ao praticar as ações, por outro lado, é capaz de dar testemunho de nossas ações egoístas e dos privilégios por estas instituídos, é capaz de denunciar a escolha que fizemos e suas conseqüências. É capaz, nessa perspectiva, de mostrar o grau de civilidade atingida pela espécie, grau este que nem de longe revela o desejável, uma vez que a polidez dos costumes é apenas um elemento, que radica na esfera da aparência, das intrincadas e nada desinteressadas relações sociais. Com efeito, o melhoramento dos costumes, de modo algum, equivale a um melhoramento moral, pois, como adverte Kant (2003, p. 16. AK, VIII, 26): "todo bem que não esteja enxertado numa intenção moralmente boa não passa de pura aparência e cintilante miséria."

Entretanto, apesar de Kant reconhecer tais problemas e tecer críticas a essas relações fundamentadas na pura aparência, tal qual fizera Rousseau, há que se observar que os antagonismos e dissimulações presentes no tratamento dos homens entre sis são previsíveis, pois há na natureza humana uma propensão para o mal, não obstante ser a disposição para o bem a marca distintiva da humanidade. Isto significa dizer, no mínimo, que, em função dessa dualidade, a tensão (a luta do princípio bom contra o mau) vai sempre marcar decisivamente o existir humano.

\footnotetext{
${ }^{1}$ Com o fim de melhor compreender os termos "cultura e civilização" é interessante atentar para o comentário a esse respeito de Menezes, pois, segundo ele, "Kant estabelece nuanças entre cultura e civilização, que seguem a ordem hierárquica do desenvolvimento das disposições. Aquela indica uma etapa anterior à civilização, quando designa todas as primeiras formas do domínio dos instintos. Esta representa um momento posterior, fortemente marcado pela aparência e pelos falsos brilhos." (MENEZES, 2010, p. 111).
} 
Por outro lado, mesmo que a intenção moralmente boa não tenha um caráter dominante no momento em que o referido pensador vive, ela não é negada ou descartada; portanto, em função da forma como ele concebe o homem, forma distinta da de Rousseau, acolhe expectativas distintas em relação a este, pois pensa o desenvolvimento humano, como bem assinalou Cassirer, a partir de uma perspectiva teleológica, sendo o desenvolvimento moral o fim término da humanidade no mundo.

É digno de nota que, no Começo conjectural da história humana (1786), Kant fala claramente do desenvolvimento das capacidades potenciais já presentes no homem, ressaltando que este é impulsionado pela razão, a fim de que saia do estado de rudeza e não mais volte a ele, "[...] a infatigável razão se interpõe e o impulsiona a desenvolver, de maneira inelutável, as capacidades nele presentes, não the permitindo retomar o estado de rudeza e simplicidade do qual o havia tirado [...]" (KANT, 2010, p. 23 - 24. AK, VIII, 115).

Esse estado de simplicidade equivale a um estado sem finalidade, capaz por esse motivo de entravar o desenvolvimento em todos os níveis, inclusive no nível ético, tornando-o, mesmo, impensável. Na Ideia, diz Kant (2003, p. 15. AK, VIII, 110), que o Estado, sem finalidade dos selvagens, "entravou todas as disposições naturais em nossa espécie, mas finalmente, por meio dos males, onde ele a colocou, obrigou-a a sair desse Estado e entrar na constituição civil, na qual todos aqueles germes podem ser desenvolvidos [...]."

Para Kant, diferentemente de Rousseau, o desenvolvimento das disposições naturais da espécie voltadas para o uso da razão é um propósito da natureza, portanto nem de longe uma violentação desta. O desenvolvimento das disposições racionais é condição de possibilidade para saída do estado de rudeza e para o melhoramento moral da espécie.

Isso justifica o porquê desse momento da civilidade ser concebido como condição de possibilidade para o aperfeiçoamento moral do homem, motivo pelo qual declara Kant (2003, p. 16. AK, VIII, 26) que se todo o progresso da humanidade se resumisse a isto, ou seja, à mera aparência, com muita razão teria Rousseau preferido o estado dos selvagens. É a intenção moralmente boa que deve ser cultivada, postas as condições para tal e não a aparência do bem. Mais uma vez Cassirer (2007, p. 181) diz, acertadamente, em suas considerações sobre Kant, que: "O que é verdadeiramente permanente na natureza humana não é um estado que ela tenha possuído em alguma ocasião antes de abandoná-lo, porém, aquilo para o qual existe e aquilo para o qual tende."

É digno de nota que essa distinção entre a aparência de moralidade e a própria moralidade antecede a Ideia de uma história universal, já estando presente na Crítica da razão pura (1781), como mostra o texto que passamos a citar:

Há na natureza humana uma certa insinceridade que, no fim de contas, como tudo o que vem da natureza, deve conter uma disposição para fins bons. Quero referir-me à inclinação que temos para esconder os verdadeiros sentimentos e manifestar certos outros, considerados bons e honrosos. É muito certo que os homens, por esta inclinação tanto para ocultar os sentimentos como para tomar uma aparência que Ihes seja vantajosa, não só se civilizam, como pouco a pouco, em certa medida, se moralizam, pois não podendo ninguém penetrar através do disfarce da decência, da honorabilidade e da moralidade, encontrará cada qual nos pretensos bons exemplos, que vê a sua volta, uma escola de aperfeiçoamento para si próprio. (KANT, 1994, p. 602, B 775- 776).

Cabe ressaltar a identificação patente, nessa passagem da primeira Crítica, de um certo sentido positivo nesse jogo da aparência, haja vista que ela pode levar à moralização. Além disso, na Crítica da razão pura, tal qual na Ideia, uma vez transformada moralmente a sociedade, a falsidade, a mera aparência de bondade e de honra não mais deverão ser acolhidas. Quanto a isto diz Kant (1994, p. 602, B 776): 
[...] logo que os princípios legítimos se desenvolveram e se transformaram em modos de pensar, essa falsidade deve, pouco a pouco, ser combatida com vigor, pois de outra maneira corrompe o coração e abafa os bons sentimentos debaixo da erva daninha da boa aparência.

$\mathrm{Na}$ Antropologia algo semelhante é dito apenas com a diferença de que o jogo da dissimulação não é apresentado como um verdadeiro engano, uma vez que, no fundo, no que tange às relações sociais, todos sabem que ninguém está sendo exatamente sincero. Assim diz Kant (2006, p. 50. AK, VIII, 151):

Feitas as contas, quanto mais os seres humanos se tornam civilizados, tanto maior é o número de atores; eles aparentam simpatia, respeito pelos outros, recato, altruísmo, sem enganar ninguém com isso, porque cada um dos demais está de acordo que não se está sendo exatamente sincero, e também é muito bom que as coisas sejam assim no mundo. Pois, porque os homens representam esse papel, as virtudes, cuja aparência apenas afetam por um longo espaço de tempo, são por fim pouco a pouco realmente despertadas e passam a fazer parte do caráter. - Enganar, porém, o enganador que há em nós mesmos, enganar a inclinação é, por sua vez, voltar a obedecer à lei da virtude, não engano, mas inocente ilusão de nós mesmos.

Mais adiante insiste ainda Kant (2006, p. 51. AK, 152):

A natureza implantou sabiamente no homem a propensão a se deixar de bom grado enganar, quer para salvar a virtude, quer para conduzi-lo a ela. A boa e honrosa decência é uma aparência exterior que infunde respeito aos outros [...]. - Em geral, tudo o que se denomina decoro (decorum) é da mesma índole, a saber, nada mais que bela aparência.

Foquemo-nos, agora, especificamente no texto da Ideia, onde não apenas civilidade e moralidade são diferenciadas, como, ainda, o conflito é apresentado, uma vez ser a mola propulsora para a cultura e para o mundo civilizado. O conflito é característico da natureza humana, razão pela qual não desaparece e, como bem lembra Santiago, não é sequer desejável seu desaparecimento. Segundo ela: "Inclusive a moralidade é o produto do conflito. [...] com efeito, há uma disposição moral no homem, porém se encontra em "germe", isto é, em espera de um campo fértil para desenvolver-se plenamente" (SANTIAGO, 2004, p. 49). Isto não pode significar, no entanto, que a sociedade política possa engendrar mecanicamente a moralidade, o que seria impossível pela própria natureza incondicionada da moral. Atentemos para a passagem emblemática da Ideia, a saber:

Dão-se então os primeiros verdadeiros passos que levarão da rudeza à cultura, que consiste propriamente no valor social do homem; aí desenvolvem-se aos poucos todos os talentos, forma-se o gosto e tem início, através de um progressivo iluminar-se (Aufklärung), a fundação de um modo de pensar que pode transformar, com o tempo, as toscas disposições naturais para o discernimento moral em princípios práticos determinados e assim finalmente transformar um acordo extorquido patologicamente para uma sociedade em um todo moral. (KANT, 2003, p. 09. AK, VIII, 21).

Destarte, um estado de inocência, onde predominaria uma vida arcádica, pastoril é, assim, na visão kantiana, diferente da rousseauísta, totalmente indesejável e inconciliável com a noção de desenvolvimento, pretendido pela natureza para o homem e cuja mola propulsora seria o conflito. Se por um lado, por meio da insociável sociabilidade, pode aflorar o que de pior há na humanidade, por outro, é, afinal, essa moeda de pouco valor, conforme diz Kant (2006, p. 51-52. AK,VIII,152-153), na Antropologia, que poderá apesar das perdas ser trocada por ouro verdadeiro. 
É que para este, ainda tomando por base a Antropologia, o sair da rudeza individual e através das relações sociais, "tornar-se um ser polido (ainda que não moral), destinado à concórdia, já é um nível superior. - O ser humano é capaz e necessita de uma educação, tanto no sentido da instrução quanto no da obediência (disciplina)". (KANT, 2006, p. 218. AK, VIII, 323).

\title{
4 | CONSIDERAÇÕES FINAIS
}

Se a forma kantiana de pensar é mais coerente do que a de Rousseau, eis o que talvez não seja possível decidir e é esta a constatação a que chega o próprio Kant na continuidade da referida passagem da Antropologia, onde admite a pertinência da forma de pensar de Rousseau, sem deixar de insistir em argumentar, é claro, na razoabilidade de suas próprias ideias. Como se segue:

\begin{abstract}
Aqui reside a questão (pró ou contra Rousseau) de saber se, segundo sua disposição natural, o caráter de sua espécie estará melhor entre a rudeza de sua natureza que entre as artes da cultura, as quais não deixam entrever um desfecho. - Antes de mais nada é preciso observar que, em todos os demais animais abandonados à própria sorte, cada indivíduo alcança sua plena destinação, mas entre os homens no máximo apenas a espécie a alcança, de modo que o gênero humano só pode avançar até a sua destinação mediante um progresso numa série imensa de gerações, onde porém a meta continua sempre à sua vista, não obstante a tendência para esse fim-último ser com freqüência tolhida, embora jamais possa retroceder. (KANT, 2006, p. 218. AK, VIII, 324).
\end{abstract}

Essa passagem da Antropologia é sui generis, pois nela salta à vista a inquietação do filósofo de Königsberg com a crítica feita pelo genebrino a ponto de assinalar que a opção por um ou outro modo de pensar não deixa entrever um desfecho. Precipitar-nos-íamos se considerássemos isto uma rendição, no entanto, seríamos levianos se não entendêssemos como uma implícita confissão do quão impressionado foi Kant por esse modo de pensar e o quão ao longo de toda sua filosofia, embora fazendo justiça ao pensamento rousseauísta, esforçou-se por ir além deste, mas sem deixá-lo de ter como fio condutor.

Tal é o que transparece, ainda, no Começo conjectural da história, ao afirmar Kant (2010, p. 26. AK, VIII, 116) acerca do genebrino:

[...] em Emílio, Contrato social e outros textos, ele busca resolver um problema ainda mais difícil: saber como a cultura deve progredir para desenvolver as disposições da humanidade, como espécie moral, conforme a sua destinação, de sorte que esta última não se oponha mais à primeira, à espécie natural.

Este é, sem dúvida, o mesmo problema que o próprio Kant se dispôs a enfrentar em boa parte de seus textos, só que através de uma argumentação fundamentada numa consideração teleológica sobre o desenvolvimento moral da espécie, que para ele progride para o melhor. Isso equivale a dizer, em última análise, que seu intenso trabalho filosófico fora, em grande parte, fruto de um insistente e recorrente diálogo com a filosofia de Rousseau, fonte constante de influência, inspiração, desejo de conciliação e de superação. 


\section{Referências}

CASSIRER, E. Rousseau, Kant, Goethe: filosofía y cultura en la Europa del siglo de las luces. Tradução Roberto Aramayo. Madrid: Fondo de Cultura Económica, 2007.

KANT, I. Antropologia de um ponto de vista pragmático. Tradução Clélia Aparecida Martins. São Paulo: lluminuras, 2006.

Começo conjectural da história humana. Tradução Edmilson Menezes. São Paulo: UNESP, 2010.

Crítica da razão pura. Tradução Manuela Pinto dos Santos. Lisboa: Calouste Gulbenkian, 1994.

. Ideia de uma história universal de um ponto de vista cosmopolita. Tradução de Rodrigo Naves e Ricardo Terra. Ricardo Terra (Org.). São Paulo: Martins Fontes, 2003.

. Kants gesammelte schriften. Königlich Preussischen Akademie der Wissenschaften. Berlin: Walter de Gruyter, 1910-1983.
. Observações sobre o sentimento do belo e do sublime. Tradução Pedro Panarra. Lisboa: Edições 70, 2012.

MENEZES, E. Apêndice. Moral e vida civilizada: notas sobre a avaliação moderna de seus nexos. In: KANT, I. Começo conjectural da história humana. São Paulo: UNESP, 2010. p. 41-131.

ROUSSEAU, J.-J. Discurso sobre a origem e os fundamentos da desigualdade entre os homens. Tradução Paul Arbousse-Bastide. São Paulo: Abril Cultural, 1983a. (Coleção Os Pensadores).

Discurso sobre as ciências e as artes. Tradução Paul Arbousse-Bastide. São Paulo: Abril Cultural, 1983b. (Coleção Os Pensadores).

. Emílio, ou, Da Educação. Tradução Roberto Leal Ferreira. São Paulo: Martins Fontes, 1999.

SANTIAGO, T. Función y crítica de la guerra en la filosofia de I. Kant. Rubí (Barcelona): Anthropos Editorial; México: Universidad Autónoma Metropolitana (UAM), 2004. 